\title{
ISLAM GAYO: STUDI TENTANG AKULTURASI ISLAM DENGAN BUDAYA LOKAL DI KABUPATEN ACEH TENGAH
}

\author{
Ali Mustafa \& Rahmat Hidayat
}

Sekolah Tinggi Agama Islam Negeri Gajah Putih Takengon

Email:ammustafa8@gmail.com

\section{Abstract:}

This paper explores the acculturation of Islam with local culture in the Gayo highlands, district of Central Aceh. The study focused on both the process of acculturation of Islam and local culture in the ceremonies of birth, marriage and death. In this process, Gayonization of Islam is dominant in comparison to Islamization of Gayo's culture. In Gayonization of Islam, the terms, actions, and equipments used in the ritual is a purely Gayo's culture, but Islamic values and teachings are inserted in it. The acculturation process occurred in four stages such as accomodating islamic preaching, identification, Gayonization, and implementation. Furthermore, the acculturation of Islam with Gayo's culture in and the ceremonies of birth, marriage, and death, can be grouped in three forms: 1) the acculturation of Islamic values with customary objects, in which the objects are ascribed as symbols of Islamic values; 2) the acculturation of Islamic values with the traditions, in which customary practice are attributed as a symbol of Islamic values; and 3) the acculturation of Islam with customary practice, in which customary practice is based on Islamic teachings. At the first and second forms, it can be said that there is a shift from a custom-based meaning to Islam-based meaning (substitution of meaning). While at the third form, occurred the infusion of Islamic values to traditional ritual (addition to the rites).

$$
\begin{aligned}
& \text { ويحاول هذا البحث أن يستكشف الثناقت بين الإسلام والثقافة المحلية في مرتفعات جايو ، منطقة }
\end{aligned}
$$

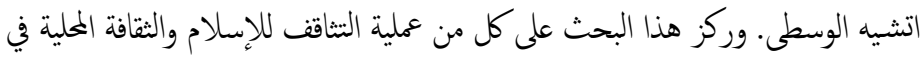

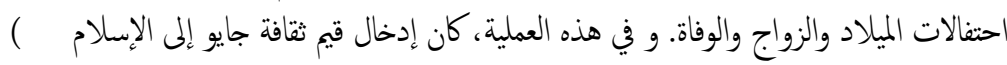


Ali Mustafa \& Rahmat Hidayat, Islam Gayo: Studi Tentang Akulturasi...

$$
\begin{aligned}
& \text { أأكثر بالنسبة لدخول القيم الإسلامية إلى ثقافة جايو ـ و في العملية }
\end{aligned}
$$

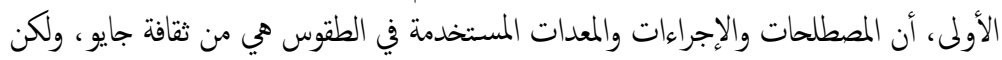

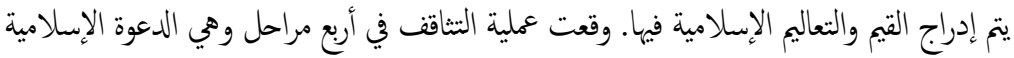

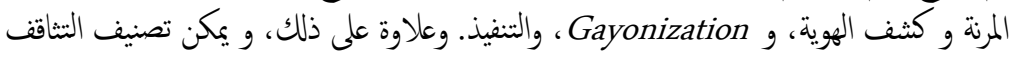

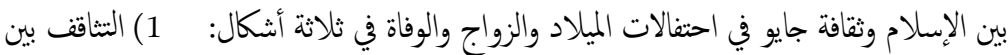

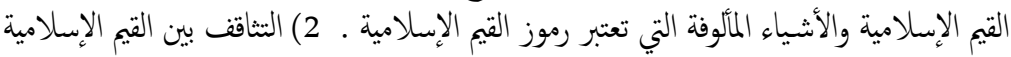

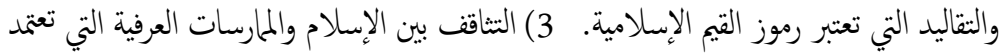

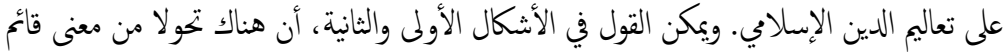

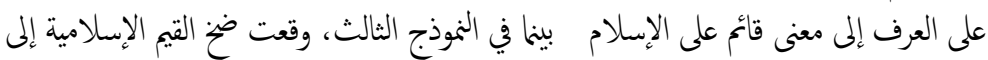

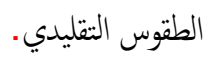

Kata Kunci: akulturasi, Islam, budaya lokal, suku Gayo

\section{Pendahuluan}

Suku Gayo adalah sebuah suku bangsa yang mendiami dataran tinggi Gayo di Provinsi Aceh bagian tengah. Wilayah tradisional suku Gayo meliputi Kabupaten Bener Meriah, Aceh Tengah dan Gayo Lues. Selain itu suku Gayo juga mendiami sebagian wilayah di Aceh Tenggara, Aceh Tamiang, dan Aceh Timur. ${ }^{1}$ Menurut sejarahnya, suku Gayo adalah bagian dari Melayu Tua yang datang dari Hindia Belakang ke Nusantara pada gelombang pertama sebelum Masehi. Mereka menetap di pantai utara dan timur Aceh serta sepanjang daerah aliran Sungai Jambo Aye, Perlak, Kuala Simpang, Wih Jernih dan hulu Sungai Peusangan yang berada di daerah Lut Tawar, Takengon. ${ }^{2}$

${ }^{1}$ M. Junus Melalatoa (ed.), Memahami Aceh Sebuah Perspektif Budaya dalam Aceh, Kembali ke Masa Depan (Jakarta: IKJ Press, 2006), h. 14.

${ }^{2}$ Mahmud Ibrahim, Mujahid Dataran Tinggi Gayo (Takengon: Yayasan Maqamammahmuda, 2007), h. 1, 9. 
Ketut Wiradnyana, seorang peneliti dari Badan Arkeologi Medan, menjelaskan bahwa masyarakat Gayo sudah mengenal sistem kepercayaan atau religi sejak masa prasejerah. Di situs Ujung Karang Kecamatan Kebayakan Aceh Tengah, Wiradnyana menemukan bukti adanya penguburan yang disertai bekal kubur berupa wadah berbahan tanah liat (gerabah) dan mata panah berbahan batu dan juga wadah yang dianyam. Adanya bekal kubur tersebut memberikan gambaran akan adanya kepercayaan terhadap kehidupan lain selain kehidupan di alam dunia. Sehingga, jenazah diberikan bekal kubur agar di dalam perjalanan ke alam lain tidak terganggu. ${ }^{3}$

Temuan arkeologis di atas menguatkan keyakinan bahwa sebelum Islam masuk ke wilayah Gayo, masyarakat Gayo masih meyakini kepercayaan animisme. Ketika agama Islam masuk ke Perlak pada abad pertama Hijriah dan berkembang pesat, animisme yang dipercaya oleh masyarakat Gayo berangsur-angsur hilang dan beralih pada kepercayaan Islam. Kepercayaan animisme yang mereka yakini dan adat istiadat yang mereka pegang teguh turun temurun sejak berabad-abad sebelum Islam, berangsur-angsur diubah dan disesuaikan dengan nilai dan norma ajaran Islam. ${ }^{4}$

Percampuran dan penyesuaian antara nilai keislaman dengan norma budaya Gayo, tercermin tidak hanya dalam perilaku budaya masyarakat, tetapi juga dalam perimestike ${ }^{5}$ Gayo yang mengandung

${ }^{3}$ Ibid.

${ }^{4}$ Mahmud Ibrahim dan AR. Hakim Aman Pinan, Syariat dan Adat Gayo, Jilid 2 (Takengon: Yayasan Maqamammahmudah, Cetakan Keempat, 2010), h. 1.

${ }^{5}$ Primestike adalah bahasa yang menggunakan kiasan yang bersifat metaforis dalam Joni, Wise Speech "Peri Mestike" in Gayo Cultural, International Journal of Linguistics, Vol.7, No.3 tahun 2015. 
Ali Mustafa \& Rahmat Hidayat, Islam Gayo: Studi Tentang Akulturasi...

prinsip tersebut antara lain yang berbunyi, "Agama urum edet, lagu zet urum sifet (Agama Islam dan adat Gayo seperti zat dengan sifat yang tidak mungkin dapat dipisahkan)". 6 Hal ini menegaskan bahwa akulturasi antara adat dan syariat Islam sangat erat dan saling menunjang. Fungsi adat untuk menunjang pelaksanaan ajaran agama Islam, merupakan prinsip budaya dalam kehidupan masyarakat Gayo. ${ }^{7}$ Adat Gayo berfungsi memelihara atau menjaga agar syariat terlaksana dengan baik, sehingga tidak terjadi pelanggaran terhadap ketentuan syariat. Adat yang berkedudukan sebagai penunjang pelaksanaan syariat menyebabkan syariat bertransformasi menjadi adat atau budaya. Begitupun sebaliknya, budaya bertransformasi menjadi agama (Islam budaya).

Penelitian ini menelusuri keberadaan Islam dalam nuansa akulturasi dengan budaya lokal di dataran tinggi gayo yang secara administratif berada di wilayah Kabupaten Aceh Tengah, Provinsi Aceh. Fokus kajian diarahkan pada dua hal. Fokus pertama berkaitan dengan proses akulturasi Islam dan budaya lokal, dan kedua tentang akulturasi Islam dan budaya lokal pada upacara kelahiran, perkawinan, dan kematian.

\section{Kerangka Teoretis}

Untuk menganalisis proses akulturasi Islam dan budaya lokal di Kabupaten Aceh Tengah, penelitian ini menggunakan teori tindakan sosial

${ }^{6}$ Mohd. Ali Djadun, "Sambutan Ketua Majelis Permusyawaratan Ulama Kabupaten Aceh Tengah", dalam Mahmud Ibrahim dan A.R. Hakim Aman Pinan, Syari'at dan Adat Istidat, Jilid 3 (Takengon: Yayasan Maqamammahmuda, Cetakan Pertama, 2005), h. viii. Lihat juga A.R. Hakim Aman Pinan, 1001 Pepatah Petitih Gayo (Takengon: Panitia Penerbitan Buku Adat dan Budaya Gayo, 1993), h. 36.

${ }^{7}$ Mahmud Ibrahim, Mujahid..., h.19-20. 
yang digagas oleh Max Weber ${ }^{8}$ sebagai paradigma. Weber, yang dalam metodologinya menggunakan verstehen atau menyatu rasa, menjelaskan bahwa makna subjektif dari perbuatan-perbuatan berdasarkan sudut pandang pelakunya. Realitas adalah realitas untuk pelakunya, bukan pengamat. Hubungan kausal-fungsional dalam ilmu empiris-positif digantikan hubungan makna dalam memahami budaya. Oleh karena itu, dalam budaya tidak akan ditemui usaha merumuskan hukum-hukum (nomotetik), tetapi hanya akan melukiskan gejala (ideografik). ${ }^{9}$

Dengan mengikuti premis Weber di atas, yang seharusnya dipahami atau ditangkap esensi dalam simbol-simbol budaya adalah makna yang tersirat. Dari sini dapat dikatakan bahwa dalam satu makna (esensi), simbol boleh berbeda otoritas dengan syarat makna masih sama. Demikian pula dengan ritus-ritus budaya. Semua pada level penampakannya (appearence) adalah simbol-smbol pengungkapan atas nilai-nilai yang diyakini sehingga dapat mengungkapkan makna subjektif dari pelakunya.

\section{Metode Penelitian}

Penelitian mengenai akulturasi Islam dan budaya Gayo ini difokuskan pada masayarakat dan budaya Gayo yang ada di Kabupaten Aceh Tengah. Pemilihan lokasi ini didasarkan hasil penelitian mutakhir yang dilakukan oleh dari Medan Sumatera Utara yang menyimpulkan bahwa nenek moyang suku Gayo ternyata terdapat di Kabupaten Aceh

\footnotetext{
${ }^{8}$ Max Weber adalah salah satu ahli sosiologi dan sejarah bangsa Jerman, lahir di Erfurt, 21 April 1864 dan meninggal dunia di Munchen, 14 Juni 1920. Weber adalah guru besar di Freiburg (1894-1897), Heidelberg (sejak 1897), dan Munchen (1919-1920).

${ }^{9}$ Kuntowijoyo, Muslim Tanpa Masjid, Esai-Esai Agama, Budaya, dan Politik dalam Bingkai Strukturalisme Transendental (Bandung: Mizan, 2001), h. 110-111.
} 
Ali Mustafa \& Rahmat Hidayat, Islam Gayo: Studi Tentang Akulturasi...

Tengah. Hal ini sebagaimana ditemukannya fosil manusia purba di situs Loyang Mendale Kecamatan Kebayakan yang memperkirakan adanya kehidupan manusia di lokasi tersebut sejak 8430 tahun yang lalu. Kegiatan penelitian ini berlangsung selama lebih kurang sepuluh bulan mulai dari penyusunan proposal hingga penyerahan laporan akhir, yang berawal dari bulan Maret 2016 dan berakhir pada bulan Desember 2016.

Dengan metode penelitian kualitatif, peneliti merupakan instrumen utama (key instrument). Hakikat peneliti sebagai instrumen kunci diaplikasikan dalam penggunaan teknik pengumpulan data. Teknik pengumpulan data tersebut meliputi wawancara, observasi, dan studi dokumentasi. Informan kunci dalam penelitian ini tiga orang, yaitu Yusin Saleh (Ketua Majelis Adat Nenggeri Gayo (MANGO)), Ibnu Hajar Lut Tawar (Tokoh Masyarakat Gayo), dan Mahmud Ibrahim (Sejarawan dan Tokoh Agama Suku Gayo) di Kabupaten Aceh Tengah. Teknik yang diterapkan untuk pemeriksaan keabsahan data adalah ketekunan pengamat, triangulasi sumber, dan pengecekan teman sejawat.

\section{Islam Gayo: Diskusi Hasil Penelitian}

1. Proses Akulturasi Islam dan Budaya Gayo

Dalam kaitan akulturasi agama dan budaya lokal, pada umumnya proses tersebut terjadi melalui dua pendekatan, yaitu pendekatan agamaisasi kultur dan pendekatan kulturisasi agama. Istilah ini diadaptasi dari istilah yang digunakan oleh M. Darori Amin ketika menganalisis proses penyebaran Islam di Jawa. Amin mengatakan bahwa proses penyebaran Islam di Jawa terdapat dua pendekatan, yaitu pendekatan Islamisasi Kultur Jawa dan pendekatan Jawanisasi Islam. Melalui pendekatan islamisasi kultur Jawa ini budaya Jawa diharapkan tampak 
bercorak Islam, baik secara formal maupun substansial. Seperti penggunaan istilah-istilah Islam, nama-nama Islam, pengambilan tokoh Islam dalam berbagai cerita, penerapan hukum dan norma-norma dalam berbagai aspek kehidupan, ini semua adalah beberapa contoh yang sering digunakan oleh para pendahulu dalam mengakulturasikan antara budaya Jawa dan Islam. ${ }^{10}$ Pendekatan kedua adalah Jawanisasi Islam, yang diartikan sebagai upaya penginternalisasian nilai-nilai Islam melalui cara penyusupan ke dalam budaya Jawa. Dalam penggunaan pendekatan yang kedua ini, nama-nama dan istilah-istilah Jawa tetep digunakan dalam pendekatan ini, namun nilai yang dikandungnya adalah nilai-nilai Islam sehingga Islam menjadi men-Jawa. Dewasa ini banyak pembuktian bahwasannya produk-produk budaya orang Jawa yang beragama Islam cenderung mengarah kepada polarisasi Islam Kejawaan atau Jawa yang Keislaman. Seperti contoh pada nama orang Abdul Razak menjadi Durajak, begitu juga dalam sebutan narimo ing pandom yang pada hakekatnya berarti tawakkal. ${ }^{11}$

Model atau pendekatan kulturisasi agama atau Jawanisasi Islam sebagaimana disebutkan Darori Amin, sebenarnya sama dengan konsep atau gagasan pribumisasi Islam yang secara geneologis dilontarkan pertamakali oleh Abdurrahman Wahid pada tahun 1980-an. Dalam "Pribumisasi Islam" tergambar bahwa Islam sebagai ajaran yang normatif berasal dari Tuhan diakomodasikan ke dalam kebudayaan yang berasal

${ }^{10}$ M. Darori Amin, Islam dan Kebudayaan Jawa (Yogyakarta: Gama Media, 2000). h. 120.

${ }^{11}$ Ibid. 
Ali Mustafa \& Rahmat Hidayat, Islam Gayo: Studi Tentang Akulturasi...

dari manusia tanpa kehilangan identitas masing-masing. ${ }^{12}$ Pribumisasi Islam telah menjadikan agama dan budaya tidak saling mengalahkan, tetapi berwujud pola nalar keagamaan yang tidak lagi mengambil bentuknya yang otentik dari agama, serta berusaha mempertemukan jembatan yang selama ini memisahkan antara agama dan budaya.

Berdasarkan analisis terhadap data tentang proses akulturasi Islam dan budaya Gayo di Kabupaten Aceh Tengah di atas, tampaknya perpaduan Islam dan budaya lokal cenderung menggunakan pendekatan kulturisasi atau pribumisasi Islam dibanding pendekatan Islamisasi kultur. Dalam hal ini, istilah-istilah, perbuatan dan peralatan adat yang digunakan dalam perkawinan adalah murni budaya. Dalam upacara kelahiran, istilah yang digunakan masyarakat untuk menyebut ritual ini adalah sinte turun mani, murni budaya. Bentuk perkawinan, dan kematian, istilah yang digunakan sinte mungerje, dan sinte mate. Namun, nilai-nilai dan prinsip Islam amat kental disisipkan dalamnya, seperti penyembelihan hewan akikah dalam turun mani, ijab kabul dan mahar dalam mungerje, serta pelaksanaan fardu kifayah dalam sinte mate.

Jika dianalisis lebih lanjut, kulturisasi Islam di dataran tinnggi Gayo adalah konsekuensi logis dari bentuk dakwah yang cenderung akomodatif. Dengan kata lain, dakwah yang dilakukan umumnya menggunakan pendekatan kultural menyebabkan Islam dengan mudah diterima oleh masyarakat Gayo, hingga pada akhirnya menyatu dengan nilai-nilai budaya setempat. Sebagaimana data yang dipaparkan oleh Mahmud Ibrahim, bahwa model dakwah yang dilakukan oleh para dai di Aceh Tengah antara lain menyisipkan nilai-nilai Islam ke dalam berbagai

${ }^{12}$ Abdurrahman Wahid, Pergulatan Negara, Agama, dan Kebudayaan (Jakarta: Desantara, 2001), h. 111. 
aspek budaya telah berkembang pada masyarakat Gayo sebelum Islam datang. Sebagaimana dicontohkan, Islam menyusup ke dalam seni, cerita rakyat, dan kata-kata adat masyarakat Gayo.

Dengan model dakwah akomodatif, para ulama yang datang ke dataran tinggi Gayo mencoba mengadopsi kebudayaan lokal secara selektif. Sistem sosial, kesenian, dan pemerintahan yang pas tidak diubah, termasuk adat istiadat, banyak yang dikembangkan dalam perspektif Islam. Hal itu memungkinkan budaya Gayo tetap beragama, walaupun Islam telah menyatukan wilayah itu secara agama.

Pada kenyataannya, kalangan ulama yang mendakwahkan Islam ke dataran tinggi Gayo telah berhasil mengintegrasikan antara ke-Islam-an dan ke-Gayo-an, sehingga budaya yang ada di daerah ini telah dianggap sesuai dengan nilai Islam. Hal ini karena Islam menyangkut nilai-nilai dan norma, bukan selera atau ideologi, apalagi adat. Oleh karena itu, jika nilai Islam dianggap sesuai dengan adat setempat, tidak perlu diubah sesuai dengan selera, adat, atau ideologi Arab. Jika itu dilakukan akan timbul kegoncangan budaya, sementara mengisi nilai Islam ke dalam struktur budaya yang ada jauh lebih efektif daripada mengganti kebudayaan.

Jika menilik kepada sejarah dakwah Islam, sebenarnya dakwah dengan cara akomodatif seperti di atas juga telah dipraktekkan oleh Rasul ketika berdakwah kepada masyarakat non-muslim Madinah. Ketika Nabi hijrah ke Madinah, masyarakat Madinah menyambut dengan iringan gendang dan tetabuhan sambil menyanyikan țala'al badru 'alaina dan seterusnya yang kemudian dalam kahazanah budaya Islam dikenal dengan Salawat Badar. Beliau selanjutnya dengan serta merta menggunakan tradisi Arab untuk mengembangkan Islam. Hal-hal yang diakomodir Rasul dari masyarakat Madinah di kala itu antara lain terlihat 
Ali Mustafa \& Rahmat Hidayat, Islam Gayo: Studi Tentang Akulturasi...

pada beberapa poin yang tercantum dalam piagam Madinah seperti tentang persatuan umat, hak asasi manusia, persaudaraan dan kerukunan umat beragama, serta persatuan sebagai warga negara. ${ }^{13}$

Selain model dakwah yang akomodatif, keberhasilan dakwah Islam masuk ke dalam sendi-sendi budaya Gayo juga dikarenakan dakwah tersebut melibatkan tokoh-tokoh yang memegang pengaruh dalam masyarakat yaitu Merah (raja), Imem (ulama), dan Petue (cerdik pandai, tokoh masyarakat). Hal ini dapat dilihat manakala ketiga unsur tersebut berpadu dalam merumuskan 45 pasal adat di Negeri Kerajaan Lingga. Tokoh-tokoh tersebut dalam budaya masyarakat Gayo merupakan unsur sarak opat orang yang didengar dan diikuti perintah, perilaku, dan pendapatnya. Hal ini dapat dilihat pada isi pasal itu sendiri yang menyatakan bahwa,

"Kampung musarak, nenggeri mureje. Sarak opat, pintu opat. Reje musuket sipet, penggawe (imem) muperlu sunet, petue musidik sasat, rayat genap mufakat (Kampung ada wilayahnya, negeri ada rajanya. Negeri dipimpin oleh empat unsur pemerintahan. Reje menegakkan keadilan, Imem memimpin amal fardu dan sunat, Petue meneliti keadaan masyarakat dan rakyat genap (mufakat)". ${ }^{14}$

Dalam istilah komunikasi, posisi orang-orang tersebut dinamakan sebagai opinion leader ${ }^{15}$. Opinion leader inilah yang kemudian

${ }^{13}$ Azhar, "Eksistensi Dakwah Rasul Pada Masyarakat Non Muslim Madinah", dalam Jurnal An-Nadwah Vol. XI No.1, Januari-Juni 2006, h. 70-71.

${ }^{14}$ Edet Nenggeri Linge Pasal 2, lihat Mahmud Ibrahim, Jilid 2, h. 7-8.

15 Istilah opinion leader sebagai sumber informasi dan pengambil keputusan dicetuskan pertama kali oleh Lazarsfeld sebagai hasil penelitiannya yang memperkenalkan "Model Komunikasi Dua Tahap". Nurudin menjelaskan bahwa opinion leader adalah mereka yang memiliki otoritas yang tinggi dan yang menentukan sikap dan perilaku pengikutnya. Lihat Nurudin, Sistem Komunikasi Indonesia (Jakarta: PT Raja Grafindo Persada, 2004), h. 154. 
menentukan atau mempengaruhi pendapat masyarakat secara kolektif. Untuk mengubah tradisi masyarakat dengan karakteristik yang demikian, biasanya cukup mengubah para opinion leader baru kemudian dari merekalah perubahan secara menyeluruh terjadi. Homanas menyatakan bahwa seseorang yang memiliki status sosial tinggi (pemimpin pendapat) akan senantiasa memelihara nilai-nilai serta norma kelompoknya sebagai syarat minimal dalam mempertahankan statusnya. Sementara dalam kenyataannya, orang berpengaruh ini dapat menjadi pendukung inovasi atau sebaliknya, menjadi penentang. Ia (mereka) berperan sebagai model di mana perilakunya (baik mendukung atau menentang) diikuti oleh para pengikutnya. ${ }^{16}$

Masyarakat Gayo di dataran tinggi Kabupaten Aceh Tengah yang semula menganut paham animisme kemudian dengan mudah beralih menjadi penganut monoteisme. Islam diserap dan mewarnai seluruh sendi kehidupan masyarakat Gayo, mulai dari sistem kepercayaan, kekerabatan, hingga kemasyarakatan. Secara teoretik, antara Islam dan budaya Gayo telah memenuhi faktor-faktor pendukung bagi terjadinya akulturasi di mana adat dan tradisi masyarakat Gayo tidak kehilangan identitasnya namun telah terwarnai oleh nilai dan ajaran Islam.

Jika menilik prinsip-prinsip dalam berakulturasi yang telah dirumuskan Koentjaraningrat ${ }^{17}$, maka terjadinya akulturasi Islam dan budaya lokal masyarakat Gayo karena memenuhi beberapa syarat atau prinsip-prinsip berikut.

\footnotetext{
${ }^{16}$ Eduard Depari, Andrews Mac dan Collin, Peranan Komunikasi Massa dalam Pembangunan, (Jakarta: Gajah Mada University Press, 1988), h. 104.

${ }^{17}$ Koentjaraningrat, Metode...., h. 450.
} 
Ali Mustafa \& Rahmat Hidayat, Islam Gayo: Studi Tentang Akulturasi...

Pertama, principle of unitility. Nilai dan ajaran Islam dapat dimanfaatkan untuk menggantikan unsur-unsur kebudayaan lama pada masyarakat Gayo. Misalnya, tradisi kenduri mate (nenggari, munujoh, nyawah loh) yang diwarnai ajaran Islam dapat menggantikan tradisi memberi makan ruh yang telah ada sebelumnya pada masyarakat Gayo ketika menganut animisme.

Kedua, principle of function. Nilai dan ajaran Islam mampu menggantikan fungsi kebudayaan lama. Misalnya, tradisi ziarah makam dalam Islam menggantikan tradisi pemujaan arwah leluhur.

Ketiga, principle of concretness. Nilai dan ajaran Islam dapat dipergunakan dengan konkrit dalam masyarakat. Misalnya, mengazankan bayi yang bisa menghindarkan dari gangguan setan dan penyembahan kepada Sang Penguasa Alam sebagai pengganti untuk aktivitas menghormati arwah leluhur dan pengkultusan kepada alam.

Keempat, principle of early learning. Penghormatan Islam terhadap ulama dan umara, sesuai dengan budaya masyarakat Gayo yang sejak dulu menghormati sarak opat yakni reje, imem, dan petue.

Kelima, principle of integration. Ajaran Islam tentang perkawinan dapat diintegrasikan dengan sistem kekeluargaan dalam budaya Gayo dan unsur sosial dengan sedekah maupun ibadah dari ajaran Islam dapat diintegrasikan dengan pola-pola kehidupan lokal masyarakat Gayo. 
Gambar 1.

Proses Akulturasi Islam dan Budaya Gayo di Kabupaten Aceh Tengah

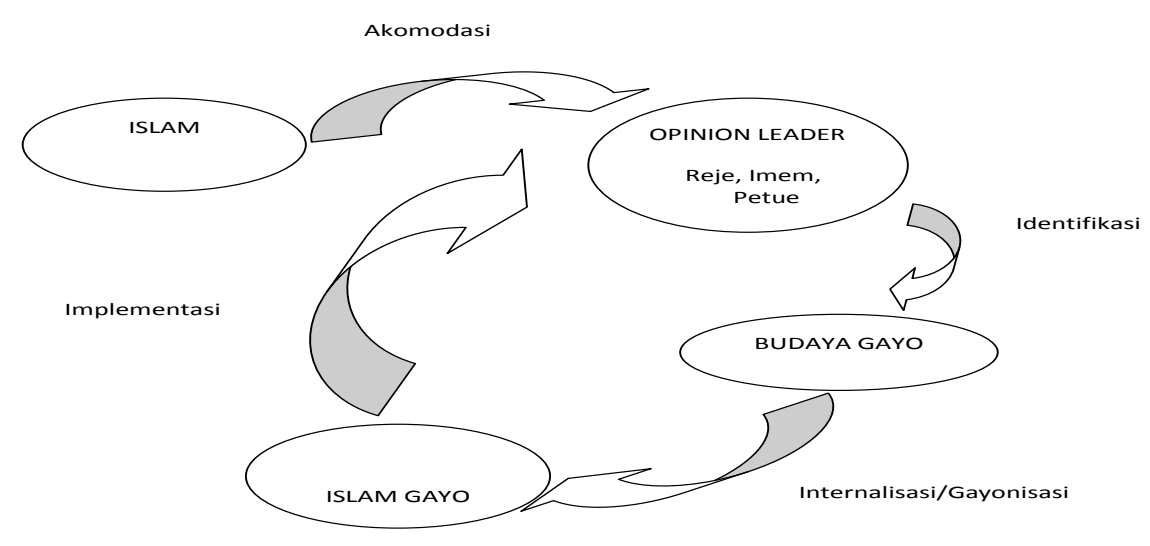

Sumber: Diolah dari data penelitian

Berdasarkan analisis temuan penelitian di atas, maka tahapan akulturasi Islam dengan budaya lokal di dataran tinggi Gayo Kabupaten Aceh Tengah dapat dibagi ke dalam empat tahap, yaitu:

a. Akomodasi. Pada tahap ini, nilai dan ajaran Islam masuk ke dataran tinggi Gayo melalui cara dakwah akomodatif. Dakwah Islam menunjukkan keterbukaannya terhadap budaya yang ada pada masyarakat Gayo.

b. Identifikasi. Pada tahap proses ini, opinion leader masyarakat Gayo yang terdiri dari reje, imem, dan petue melakukan identifikasi mana saja nilai budaya yang bertentangan dengan nilai-nilai atau ajaran Islam. Tahap ini merupakan tahap di mana nilai budaya mengalami konfrontasi dengan nilai-nilai Islam. 
Ali Mustafa \& Rahmat Hidayat, Islam Gayo: Studi Tentang Akulturasi...

c. Internalisasi/Gayonisasi Islam. Setelah teridentifikasi nilai-nilai budaya yang bertentangan atau tidak sesuai dengan nilai-nilai Islam dalam berbagai ritual masyarakat Gayo, maka secara perlahan nilai-nilai Islam lah yang dimasukkan ke dalam adat. Dengan demikian, tahap ini bisa disebut sebagai tahap penyesuaian.

d. Implementasi. Pada tahap ini nilai dan prinsip Islam telah terelaborasi dalam praksis, sistem, dan nilai budaya Gayo. Misalnya nilai-nilai Islam terelaborasi dalam bentuk hukum adat masyarakat Gayo sebagaimana tertuang dalam 45 Pasal Adat Negeri Lingga. Pada tahap ini, nilai Islam menjadi identik dengan nilai budaya Gayo, sehingga dapat disebut sebagai Islam Gayo.

Tahapan proses tersebut terus berlangsung secara simultan sepanjang terjadi dialektika Islam dan budaya Gayo. Artinya, manakala ada praktek budaya yang dinilai oleh tokoh agama bertentangan dengan nilai-nilai Islam maka secara perlahan budaya tersebut dimodifikasi tanpa merubah bentuk aslinya.

2. Akulturasi Islam dan Budaya Gayo dalam Upacara Kelahiran, Perkawinan, dan Kematian

Berdasarkan temuan penelitian, dapat dipahami bahwa cukup jelas kiranya nilai-nilai dan ajaran Islam telah diadopsi menjadi bagian dari prosesi upacara adat baik ketika menyambut kelahiran, perkawinan, maupun kematian. Pada upacara turun mandi, penggunaan beragam tumbuhan dalam ritual petawaren adalah budaya, namun ritual tersebut kemudian diberikan makna-makna yang didasarkan pada ajaran Islam. Ritual beguru, semah, basuh pumu, petawaren yang juga dalam sinte 
mungerje juga simbol-simbol yang kemudian dimaknai secara islami. Demikian pula ritual nenggari, munujoh, dan nyawah loh dalam sinte mate adalah ritual budaya yang sarat dengan nilai dan ajaran Islam. Dengan demikian, ritus-ritus budaya tersebut semua pada level penampakannya (appearence) adalah simbol-simbol budaya namun merupakan pengungkapan atas nilai-nilai Islam sebagaimana yang diyakini oleh pelakunya. Tabel berikut menggambarkan beberapa ritual dalam upacara kelahiran, perkawinan, dan kematian pada masyarakat yang telah membaur dengan nilai atau ajaran Islam itu sendiri.

\section{Tabel 1}

Beberapa Ritual/Benda Pada Upacara Kelahiran, Perkawinan, dan

Kematian Pada Masyarakat Gayo Di Kabupaten Aceh Tengah dan

Percampurannya dengan Makna/Nilai/Ajaran Islam

\begin{tabular}{|c|c|c|}
\hline $\begin{array}{l}\text { Nama } \\
\text { Upacara }\end{array}$ & $\begin{array}{l}\text { Nama Ritus/ } \\
\text { Benda Adat }\end{array}$ & $\begin{array}{l}\text { Makna/Nilai/Ajaran Islam Yang } \\
\text { Muncul }\end{array}$ \\
\hline \multirow{7}{*}{$\begin{array}{l}\text { Sinte } \\
\text { Mungerje }\end{array}$} & Tatang Batil & Kewajiban istri memuliakan suami \\
\hline & Semah Pincung & Kewajiban suami memberi nafkah \\
\hline & Semah Tunggel & Kewajiban istri menaati suami \\
\hline & Mujule Gule/Wih & Kewajiban memuliakan orangtua \\
\hline & Munginte & Anjuran mengkhitbah \\
\hline & Teniron & Perintah memberi mahar \\
\hline & I sawahan Ukum & $\begin{array}{l}\text { Syarat dan rukun nikah: ijab qabul, } \\
\text { khutbah, wali, saksi nikah, mahar }\end{array}$ \\
\hline $\begin{array}{l}\text { Sinte } \\
\text { Turun } \\
\text { Mani }\end{array}$ & Mengazankan bayi & $\begin{array}{l}\text { Doa dan harapan agar anak } \\
\text { mengamalkan syahadat dalam } \\
\text { proses kehidupannya, terhindar } \\
\text { dari gangguan setan, Sunnah } \\
\text { mengazankan bayi }\end{array}$ \\
\hline
\end{tabular}


Ali Mustafa \& Rahmat Hidayat, Islam Gayo: Studi Tentang Akulturasi...

\begin{tabular}{|c|c|c|}
\hline & Munos Gerel & $\begin{array}{l}\text { Doa dan harapan yang baik untuk } \\
\text { kehidupan bayi, ajaran Islam } \\
\text { tentang pemberian nama yang } \\
\text { baik. Percampuran bahasa Gayo } \\
\text { dengan bahasa islami seperti Ibnu } \\
\text { Hajar Lut Tawar. }\end{array}$ \\
\hline & Mencukur rambut & $\begin{array}{l}\text { Simbol membersihkan diri, perilaku } \\
\text { sedekah, Sunnah mencukur rambut } \\
\text { bayi }\end{array}$ \\
\hline & Menyembelih kambing & $\begin{array}{l}\text { Simbol rasa syukur dengan berbagi } \\
\text { pada fakir dan miskin, tebusan } \\
\text { untuk anak, Sunnah }\end{array}$ \\
\hline & $\begin{array}{l}\text { Menyuap Madu \& } \\
\text { Santan }\end{array}$ & $\begin{array}{l}\text { Doa tafaul agar anak memiliki } \\
\text { pekerti yang baik, bagus tutur } \\
\text { katanya, Sunnah men-tahnik bayi }\end{array}$ \\
\hline & $\begin{array}{lr}\text { Benda } & \text { Petawaren } \\
\text { (Batang } & \text { Teguh, } \\
\text { Dedingin, } & \text { Celala, dan } \\
\text { Bebesi) } & \end{array}$ & $\begin{array}{l}\text { Doa tafaul agar anak teguh } \\
\text { pendirian (istiqamah) dalam } \\
\text { beragama, memperoleh rezki yang } \\
\text { berlimpah, menjadi generasi yang } \\
\text { baik dan maju, memiliki fisik yang } \\
\text { kuat }\end{array}$ \\
\hline Sinte Mate & Bertukam & $\begin{array}{l}\text { Saling menolong (ta'awun) } \\
\text { berdasarkan Hadis/Sunnah }\end{array}$ \\
\hline & Turun Met & $\begin{array}{l}\text { Ajaran Islam tentang memandikan, } \\
\text { mengafani, mensalatkan, dan } \\
\text { menguburkan jenazah berdasarkan } \\
\text { Sunnah }\end{array}$ \\
\hline & Nenggari & $\begin{array}{l}\text { Bersedekah, membaca Alquran, } \\
\text { berdoa, saling menasehati tentang }\end{array}$ \\
\hline
\end{tabular}




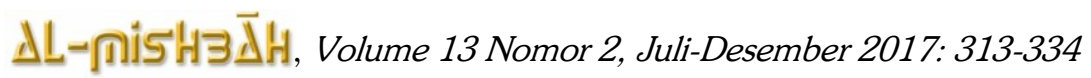

\begin{tabular}{|l|l|l|}
\hline \multirow{2}{*}{} & Munujoh & kesabaran \\
\cline { 2 - 3 } & $\begin{array}{l}\text { Bersedekah, membaca Alquran, } \\
\text { berdoa, saling menasehati tentang } \\
\text { kesabaran }\end{array}$ \\
\cline { 2 - 3 } & $\begin{array}{l}\text { Nersedekah, membaca Alquran, } \\
\text { berdoa, saling menasehati tentang } \\
\text { kesabaran }\end{array}$ \\
\cline { 2 - 3 } & Ziarah Kubur & $\begin{array}{l}\text { Membaca Alquran, berdoa, anjuran } \\
\text { berziarah }\end{array}$ \\
\hline
\end{tabular}

Sumber: Data Penelitian

Bila dilakukan analisis terhadap percampuran antara Islam dan ritual-ritual pada upacara kelahiran, perkawinan, dan kematian sebagaimana ditunjukkan tabel di atas, maka akulturasi Islam dan budaya Gayo setidaknya dapat diklasifikasikan dalam tiga bentuk, yaitu:

1. Percampuran Nilai Islam dengan Benda Adat. Dalam upacara kelahiran, perkawinan, dan kematian terdapat penggunaan bendabenda sebagai perelengkapan adat pada bagian atau prosesi tertentu. Benda-benda tersebut dapat dilihat seperti penggunaan kelapa pada upacara kelahiran; daun celala dan kawan-kawannya pada upacara perkawinan. Pada mulanya, benda-benda tersebut memiliki makna adat sendiri, namun ketika Islam masuk pemaknaan benda dikaitkan sebagai simbol-simbol yang bernuansa islami.

2. Percampuran Nilai Islam dengan Perbuatan Adat. Akulturasi pada bentuk ini adalah pemaknaan perilaku adat sebagai simbol nilai yang bernuansa Islam. Semah tunggel, dalam prosesi adat perkawinan, kemudian diberi makna sebagai bentuk penghormatan istri kepada suami sebagaimana itu didasarkan pada ajaran Islam. 
Ali Mustafa \& Rahmat Hidayat, Islam Gayo: Studi Tentang Akulturasi...

3. Percampuran Ajaran Islam dengan Perbuatan Adat. Pada bentuk yang terakhir ini, perilaku adat merupakan perbuatan yang diadopsi atau didasarkan pada ajaran Islam. Contohnya adalah prosesi ijab kabul pada upacara pernikahan dan menyembelih hewan pada upacara kelahiran.

Pada bentuk pertama dan kedua bisa disebut yang terjadi adalah pola pengalihan atau penggantian makna yang diberikan adat kepada pemaknaan yang islami (subtitution of the meaning). Sedangkan pada bentuk akulturasi yang ketiga, pola yang terjadi adalah memasukkan atau menambahkan ritual Islam ke dalam ritual adat (addition to the rites). Ritual masyarakat Gayo dalam upacara kelahiran, perkawinan, dan kematian yang ditentukan oleh bagaimana masyarakat memberikan pemaknaan terhadap perbuatan dan benda-benda yang digunakan seperti tersebut di atas, pada intinya mendukung teori tindakan sosial yang digagas oleh Max Weber.

\section{Penutup}

Dalam proses akulturasi Islam dan budaya Gayo di Kabupaten Aceh Tengah, tampaknya pendekatan Gayonisasi Islam lebih dominan terjadi dibanding pendekatan Islamisasi Gayo. Dalam pendekatan Gayonisasi Islam ini, istilah-istilah, perbuatan, dan peralatan adat yang digunakan dalam ritual adalah murni budaya Gayo, tapi nilai-nilai dan ajaran Islam disisipkan di dalamnya. Proses akulturasi tersebut berlangsung secara bertahap. Setidaknya ada empat tahapan yang dilalui, yaitu tahap dakwah Islam akomodatif, identifikasi, gayonisasi, dan implementasi. 
Adapun bentuk akulturasi Islam dan budaya Gayo dalam upacara kelahiran, perkawinan, dan kematian dapat dikelompokkan dalam tiga bentuk, yaitu 1) Percampuran nilai Islam dengan benda adat, di mana padanya terdapat pemaknaan benda sebagai simbol-simbol yang bernuansa Islam; 2) Percampuran nilai Islam dengan perbuatan adat, di mana terdapat pemaknaan perilaku adat sebagai simbol nilai yang bernuansa Islam; dan 3) Percampuran ajaran Islam dengan perbuatan adat, di mana perilaku adat yang didasarkan atau diadopsi pada/dari ajaran Islam. Pada bentuk pertama dan kedua bisa disebut yang terjadi adalah pola pengalihan atau penggantian makna yang diberikan adat kepada pemaknaan yang islami (subtitution of the meaning). Sedangkan pada bentuk akulturasi yang ketiga, pola yang terjadi adalah memasukkan atau menambahkan ritual Islam ke dalam ritual adat (addition to the rites).

\section{Daftar Pustaka}

Abraham, M. Francis. Modern Sociological Theory: An Introduction. Oxford: Oxford University Press, 1982.

Barker, Larry L. Communication, edisi ke-3. Englewood Cliffs, N.J.: Prentice Hall, 1984.

Bisri, Cik Hasan \& Eva Rufaidah (Ed.). Model Penelitian Agama dan Dinamika Sosial: Himpunan Rencana Penelitian. Jakarta: RajaGrafindo Persada, 2002.

Bungin,Burhan. Penelitian Kualitatif: Komunikasi, Ekonomi, Kebijakan Publik, dan Ilmu Sosial Lainnya. Jakarta: Kencana, 2008.

Departemen Agama RI. Al-Qur'an dan Terjemahnya. Bandung: CV. Penerbit Jumnatul 'Ali-Art (J-ART), 2004. 
Ali Mustafa \& Rahmat Hidayat, Islam Gayo: Studi Tentang Akulturasi...

Departemen Pendidikan Dan Kebudayaan. Kamus Besar Bahasa Indonesia, edisi ke-3. Jakarta: Balai Pustaka, 2003.

Effendi, Onong Uchjana. Dinamika Komunikasi. Bandung: PT. Remaja Rosdakarya, 1989. Ilmu, Teori dan Filsafat Komunikasi, Cet.ke-1. Bandung: PT.

Citra Aditya Bakti, 1993. -. Spektrum Komunikasi. Bandung: Mandar Maju, 1994.

-----------. Ilmu Komunikasi, Teori dan Praktek, Cet.ke-18. Bandung: PT. Remaja Rosdakarya, 2004.

Gamble, Teri Kwal \& Micael Gamble. Communication Works. New York: Random Hosue, 1984.

Gondokusumo, A. A. Komunikasi Penugasan: Bagi Eksekutif, Supervisor dan Karyawan. Jakarta: Gunung Agung, 1980.

Gunawan, K. Adi. Kamus Lengkap: Inggris-Indonesia, Indonesia-Inggris, Cet. Ke-XIII. Surabaya: Penerbit Kartika, 2008.

Hardjana, Agus M. Komunikasi Intrapersonal \& Interpersonal. Yogyakarta: Kanisius, 2003.

Hurgronje, C. Snouck. Gayo: Masyarakat dan Kebudayaannya Awal Abad ke- 20, terj. Hatta Hasan Aman Asnah. Jakarta: Balai Pustaka, 1996.

Ibrahim, Mahmud dan A.R. Hakim Aman Pinan. Syari'at dan AdatIstiadat, Jilid I. Takengon, Aceh Tengah: Yayasan Maqamammahmuda, 2002.

Syari' at dan Adat-Istiadat, Jilid II. Takengon, Aceh Tengah: Yayasan Maqamammahmuda, 2010. 
Syari' at dan Adat-Istiadat, Jilid III. Takengon, Aceh Tengah: Yayasan Maqamammahmuda, 2005.

Jafar, Ny.A.S. Upacara Adat Pengantin Gayo. Aceh Tengah: Depdikbud Aceh Tengah,1983.

Kholil, Syukur. Metodologi Penelitian Komunikasi. Bandung: Citapustaka Media, 2006 Komunikasi Islami. Bandung: Citapustaka Media, 2010.

Kriyantono, Rachmat. Teknik Praktis Riset Komunikasi: Disertai Contoh Praktis Riset Media, Publik Relations, Advesting, Komunikasi Organisasi, Komunikasi Pemasaran. Jakarta: Kencana Prenada Group, 2006.

Leathers, Dale G. Nonverbal Communication Systems. Sydney: Allyn and Bacon Inc., 1976.

Liliweri, Alo. Wacana Komunikasi Organisasi. Bandung: Mandar Maju, 2004.

Melalatoa, M. J. Kebudayaan Gayo. Jakarta: Balai Pustaka, 1982.

Milles, Matthew B. dan A. Michael Huberman. Analisis data kualitatif, terj. Tjetjep Rohendi Rohidi. Jakarta: Universitas Indonesia, UI Press, 1992.

Moleong. Lexi J. Metodologi Penelitian Kualitatif. Bandung: Remaja Rosdakarya, 2004.

Mulyana, Deddy. Ilmu Komunikasi (Suatu Pengantar), cet. ke-4. Bandung: Remaja Rosdakarya, 2002.

Metodologi Penelitian Kualitatif. Bandung: Remaja Rosdakarya, 2004.

Ilmu Komunikasi: Suatu Pengantar. Bandung: Remaja Rosdakarya, 2005. 
Ali Mustafa \& Rahmat Hidayat, Islam Gayo: Studi Tentang Akulturasi...

Narbuko, Cholid dan Abu Achmadi. Metodologi Penelitian. Jakarta: Bumi Aksara, 2003.

Nasution. S. Metodologi Research. Jakarta: PT. Bumi Aksara, 2003.

Nurudin. Sistem Komunikasi Indonesia. Jakarta: PT RajaGrafindo Persada, 2008.

Paeni, Mukhlis. Riak di Laut Tawar. Jakarta: Arsip Nasional Republik Indonesia kerjasama dengan Gadjah Mada University Press, 2003.

Poerwadarminta, W. J. S. Kamus Besar Bahasa Indonesia. Jakarta: Balai Pustaka, 1983.

Rachmadi, F. Informasi Dan Komunikasi. Bandung: PT. Alumni, 1988.

Rakhmat, Jalaluddin. Psikologi Komunikasi. Bandung: PT. Remaja Rosdakarya, 2007.

Ruslan, Rosyadi. Metode Penelitian Publik Relations dan Komunikasi. Jakarta: Raja Grafindo Persada, 2004.

Santoso, Edi dan Mite Setiansah. Teori Komunikasi. Yogyakarta: Graha Ilmu, 2010.

Tantawi, Isma dan Bunyamin S. Pilar Pilar kebudayaan Gayo Lues. Medan: USU Press, 2011.

Verderber, Rudolph F. \& Kathleen S. Verderber. Communicate. USA: Wadsworth, 2005.

West, Richard and Lynn H. Turner. Introducing Communication Theory: Analysis and Application. New York: McGraw Hill, 2007. 